\title{
Mujer en transición: La poesía de Clara Janés
}

\author{
Women in transition: The poetry of Clara Janés
}

\section{María Teresa Navarrete Navarrete \\ mariateresa.navarrete@moderna.uu.se \\ Uppsala Universitet, Suecia}

Recepción: 12 Agosto 2019

Aprobación: 10 Mayo 2020

Publicación: 02 Noviembre 2020

Cita sugerida: Navarrete Navarrete, M. T. (2020). Mujer en transición: La poesía de Clara Janés. Olivar, 20(32), e083. https://doi.org/10.24215/18524478e083
Resumen: Este artículo estudia la poesía de Clara Janés escrita durante los años cercanos a la Transición (1975-1978) con el propósito de examinar la evolución que se produce del sujeto mujer a lo largo de este periodo de su trayectoria. Para ello, consideraré los poemarios escritos por Janés desde 1973 hasta 1986 y organizaré mi estudio en tres niveles. En primer lugar, abordaré los presupuestos culturales que definen a la mujer escritora en los años del tardofranquismo y de la primera democracia. En segundo lugar, explicaré el impacto que la crisis creativa y personal de Janés genera en su trayectoria y en qué medida influye en esta etapa el descubrimiento de la poesía de Vladimír Holan. Y, en tercer lugar, estudiaré la cercanía que la poesía de Janés publicada en los ochenta guarda con las reivindicaciones feministas españolas de aquellos años. A través de estos tres niveles de análisis, mi objetivo final es demostrar que estas obras pertenecen a una misma fase creativa dominada por la conquista de la identidad femenina.

Palabras clave: Clara Janés, Poesía española, Transición, Mujer, Feminismo español.

Abstract: The article studies the poetry of Clara Janés written during the years close to the Spanish transition (1975-1978). My proposal is to examine the evolution experienced by the identity of women during this period of their literary career. For that, I will consider the collections of poems written by Janés from 1973 to 1986. I will organize my study in three levels. First, I examine the cultural assumptions about women writers in the last years of Francoism and the first years of democracy. Secondly, I will assume the effect of the personal and creative crisis and the influence of Vladimír Holan on the work of Janés. In the third place, I will study the closeness between the works of Janés written in the eighties and the Spanish feminist claims of these years. Through these three levels, the main objective of this article is to demonstrate that these works of poetry belong to a creative phase dominated by the conquest of a woman's identity.

Keywords: Clara Janés, Spanish poetry, Transition, Women, Spanish feminism. 


\section{INTRODUCCIÓN}

Cuando se lee la obra de Clara Janés no se percibe en una primera lectura que estemos ante literatura sobre la mujer, literatura para la mujer o literatura feminista. Sin embargo, cuando se ahonda en su análisis, pronto se descubre que la obra de Janés se disputa en el territorio de la construcción del sujeto y, siendo más específicos, en la construcción del sujeto mujer, proceso siempre en activo que muta con la alteración -con el trastorno-del exterior. En este sentido, la obra de Clara Janés, que se inicia en los años sesenta y que se consolida en los primeros años de la Democracia española, se presenta especialmente proclive para estudiar cómo afecta en la obra de una poeta el cambio de ciclo histórico que tiene lugar con el paso de la Dictadura a la Democracia. Para estudiar este proceso, me serviré de los poemarios Las estrellas vencidas (1964), Limite bumano (1973, escrito de 1963 a 1965), En busca de Cordelia (1975, escrito entre diciembre de 1971 y noviembre de 1972), Libro de alienaciones (1980), Eros (1981), Vivir (1983) y Kampa (1986). En el examen de esta fase de la poesía de Janés, apuesto por acoger estos poemarios desde un punto de vista integrador con la intención de demostrar que forman parte de un mismo relato lírico.

La crítica, al abordar esta franja de la trayectoria lírica de Clara Janés, coincide en hacer referencia a tres ejes definitorios. En primer lugar, se señala la distancia de los dos primeros libros, Las estrellas vencidas y Limite humano, con respecto a En busca de Cordelia, Kampa y los venideros. Esto se debe a que tanto Las estrellas vencidas como Limite humano se escriben y publican durante el franquismo bajo el último impulso de la importancia de la función social del arte, mientras que En busca de Cordelia y los siguientes se concentran en la conquista de una nueva mismidad. En segundo lugar, también se destaca la estructura mítica del poemario En busca de Cordelia, en el que el yo poético se lanza a un "viaje iniciático" (Keefe Ugalde, 1990, p. 518) donde prima la conquista de una nueva identidad de mujer. Esta transición, que comienza con la ruptura con la identidad antigua, pasa por la nulidad -Janés sitúa el foco, como mencionaré más adelante, en el silencio y en la duda para describir al sujeto en esta fase (Keefe Ugalde, 1993, p. 193)-, y finalmente culmina en la reconversión. La naturaleza de este proceso donde están presentes las parejas caída y ascensión y luz y sombra han llevado acertadamente a señalar, en tercer lugar, las concomitancias entre la poesía janesiana con la mística (Engelson, 1995, pp. 245-246; Garriga, 2014, pp. 60-66).

Aunque estoy de acuerdo con estos análisis de la crítica, pienso que sobre ellos prevalece, como ya he mencionado, la disputa que la poesía Janés establece con la construcción de su mismidad. Este proceso no solo se juega a nivel interno. Una vez que se conquista esta nueva identidad de mujer, la manera en la que el sujeto se relaciona con el mundo se reactualiza, tal y como se observa en los últimos poemarios de esta serie, Eros y Vivir. Para abordar la reflexión que Janés mantiene acerca de la identidad y del género en estos libros, me voy a servir de los caminos metodológicos que Marta Lamas (1994, pp. 3-31) propone para estudiar la construcción social del género. Lamas señala la fortaleza con la que la sociedad establece las diferencias entre los géneros y distingue tres fuentes principales de representación a la hora de fijar redes de imágenes. Estas son: 1) Preconceptos culturales; 2) Experiencia personal; 3) Ideología, entendida como discurso social compartido. Organizaré, por tanto, mi análisis de la poesía janesiana a partir de estos tres ejes con el propósito de demostrar cómo se enfrenta el yo lírico a cada estadio de representación social del género para lograr la conquista del sujeto-mujer.

\section{Preconceptos culturales: Literatura y MUJer}

Con la noción de preconceptos culturales hago referencia al discurso que la sociedad posee sobre el sujeto y sobre el lugar que debe ocupar de acuerdo a las diferenciaciones que la propia sociedad realiza. En el caso que nos ocupa, el del conjunto de ideas que la sociedad mantiene en cuanto al género, las diferenciaciones entre las conductas, las actividades y las esferas que debían de ocupar hombres y mujeres se presentan especialmente bien definidas en los años sesenta, cuando Clara Janés comienza a escribir. 
La intervención de la mujer en la esfera pública de la sociedad franquista, con independencia de la clase de red a la que pertenezca, se recibe desde la óptica de la tutela masculina. Su participación se define en términos de pasividad según la definición que el franquismo había otorgado a la mujer. La mujer en la posguerra había quedado relegada al ámbito doméstico. El modelo social franquista, profundamente católico y machista, había reducido sus horizontes a los de ser esposa y madre (Payne, 1982, p. 19; Rodríguez Puértolas, 1986, pp. 25-26). Aquellas que lograban superar estos estrechos límites y desarrollaban una identidad como escritoras, conseguían a través de la palabra literaria no doblegarse ante el doble silencio que les imponía la condición de ser mujeres y súbditas de un sistema dictatorial (Payeras, 2009).

Existe un testimonio elocuente acerca de los comienzos de Clara Janés en la esfera literaria y cómo estos preconceptos sobre la definición del sujeto según el género se activan. Aunque estas nociones no funcionan a modo de obstáculo o prohibición -Janés es hija del editor y poeta Josep Janés y crece siendo testigo de primera línea del mundo editorial y literario de la primera posguerra-, sí aparecen como una variable de diferenciación. Aludo a la correspondencia que la madre de Janés, Esther Nadal, sostiene con Concha Lagos (1907-2007), directora de la revista Cuadernos de Ágora (1955-1964) y la editorial Ágora (1955-1964), para interceder por la carrera literaria de su hija, que en el año 1962, era todavía una mujer muy joven (1962: 22654/110). En esta carta, Nadal hace referencia a que Janés es mujer y, siendo así, considera más apropiado que sea otra mujer la que introduzca a su hija en el ambiente literario. En este caso, se aprecia bien cuál es la posición de sujeto "mujer y escritora" dentro de la esfera literaria: se contempla su participación, pero se exige que el derecho de entrada sea otorgado por otra mujer.

La fórmula de representación bajo la que la figura de Clara Janés resulta acogida en estos años -joven mujer poeta en la esfera literaria del franquismo- conduce a que sus primeros poemas se publiquen en Cuadernos de Ágora (1961, s.p.; 1963, s.p.), al igual que su primer libro, Las estrellas vencidas, que también aparece en la editorial Ágora. Esto no quiere decir que publicar en Ágora en aquellos años fuera una mala opción, más bien lo contrario a la luz de los estudios de María José Porro y Blas Sánchez Dueñas (2015), pero sí me parece oportuno señalar que en la elección de esta red literaria interviene el axioma del género.

En este sentido, pienso que el segundo poemario de Clara Janés, Limite humano, parte precisamente de esta reflexión y se interroga acerca del uso de las categorías dadas por nuestro alrededor para pensarnos y construir nuestra imagen y la concepción que tenemos sobre nosotros mismos. El título de este libro refleja esta dirección sobre los límites que nos imponen y nos imponemos en la construcción de nuestra mismidad. El primer poema de significativo título, "A los indiferentes", se presenta a modo de declaración de intenciones: "Hay que levantar / el mundo / con la cuerda / de la vida. Sois el polvo de la tierra, / indiferentes. / Ahora no. / Ahora no. / Esperad la muerte." (1973, p. 11). Se aprecia en este poema la rebeldía ante el inmovilismo y una posición muy rotunda acerca de la inutilidad de la aceptación de los límites otorgados.

Sin embargo, cuando se aborda la cuestión del género, la ruptura no se presenta de manera tan radical. Es entonces cuando se advierte que gran parte de la identidad está arraigada en esta diferenciación. El poema "Aquí" es a mi juicio el más ilustrativo de esta línea:

El Valle, los ríos y las cumbres,

El pájaro que vuela.

\author{
El hombre que imagina \\ Su ahora \\ cada día. \\ Aquí \\ la lluvia cae \\ Y la amapola blanca se deshoja.
}




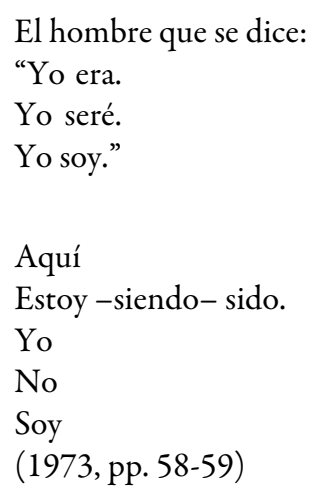

Como se aprecia en este poema, se advierte un mismo alrededor, un "aquí" compartido por dos sujetos diferenciados: el sujeto lírico (mujer) y el hombre. Para el hombre el aquí se percibe prometedor y libre a través de esa imagen del "pájaro que vuela" y por eso puede "imaginar su ahora cada día”. Este aquí contrasta con otro aquí en decrepitud que podemos asociar con el aquí del yo lírico: "la lluvia cae", "la amapola blanca se deshoja”. Del mismo modo, el hombre se define a sí mismo desde la posibilidad de existencia en el tiempo pasado, presente y futuro. Pero, por el contrario, el yo lírico no tiene el mismo campo de acción. Se anula el futuro, y el presente y el pasado aparece a través del gerundio y del participio del verbo ser - "Estoy siendo sido"-, bajo una representación no plena, para finalmente identificar su existencia desde la nulidad: "Yo no soy".

Al contrario de lo que ocurría con otros poemas del libro, en esta composición la rebeldía no consiste en rechazar los límites otorgados, sino en percibir, en descubrir, que la definición de la mismidad se sustenta en la nulidad y que para desactivarla va a ser necesario abandonarla. Esta dirección va a ser la que se explore en los próximos poemarios de la autora como en En busca de Cordelia o El libro de las alienaciones.

\section{EXPERIENCIA PERSONAL: CRISIS y DESCUBRIMIENTO DE VlADIMIR HolaN}

Para adentrarnos en En busca de Cordelia y El libro de las alienaciones y comprender el cambio de ciclo lírico que estos emprenden, es útil no perder de vista la biografía de la autora. Entramos, por tanto, en el ámbito de la experiencia personal, un factor que igualmente influye en la representación del mundo.

Limite humano termina de escribirse en 1963 y hasta 1973, fecha de publicación de En busca de Cordelia, Janés experimenta una crisis personal y creativa a la que la propia autora alude para explicar este giro lírico. Janés confiesa en el volumen Conversaciones y poesía de la profesora Keefe Ugalde, que este poemario se escribe cuando había vivido "una etapa matrimonial terrible y se refleja todo" (1991, p. 41). Y, con respecto a la crisis creativa, Janés destaca la importancia de la lectura en 1971 de Una noche con Hamlet (1964) del poeta checo Vladimír Holan (1905-1980), imprescindible para romper el letargo creativo que atravesó durante seis años. Una noche con Hamlet pertenece a la tercera fase de la escritura de Holan, la más metafísica de su trayectoria, y llega a Clara Janés por medio de la traducción española de Josef Forbelský y Guillermo Carnero que se publicó en España en $1970^{1}$. La autora relata qué supuso descubrir la poesía de Holan del siguiente modo: "Tras seis años de abandono de la poesía, seis años de hallarme en estado latente, [...] yo iba a mi propio ser, por la palabra de aquel poeta checo" (2005b, p. 18). El descubrimiento de Holan devuelve a Janés a la poesía, pero al mismo tiempo siente que los versos del checo explican su interioridad en los términos que la propia Janés no encontraba. La poesía de Holan, sirve, por tanto, de impulso para que Janés emprendiera en su siguiente poemario, En busca de Cordelia, la definición de su mismidad. Su influencia se explicita desde el pórtico del volumen en el que aparecen los versos finales del poema "Noche de estampidos" del poemario Dolor: "Ya nada presentimos y luego nos quedamos asombrados...".

Tanto la crisis matrimonial como el descubrimiento de Holan, circunstancias ambas que provienen de la experiencia vital, modifican el pulso de la poesía janesiana que en esta segunda etapa se dirige hacia la 
creación de una mismidad en clave de mujer. En busca de Cordelia se presenta como el símbolo de esta creación del ser y puede interpretarse como una de las obras más feministas de la autora. De acuerdo con Keefe Igualde (1994), En busca de Cordelia se plantea como un relato lírico de auto-descubrimiento, donde el yo lírico se enfrenta por primera vez sola al futuro. Este proceso se configura a través de una estructura que recuerda a los relatos heroicos, donde el sujeto pasa por distintas pruebas, aquí estados psíquicos, que debe transitar si quiere conquistar una nueva identidad basada no en una relación de subordinación con respecto al hombre, sino fraguada en la emancipación y la libertad de la mujer. Es posible advertir con facilidad las estrategias discursivas que Janés adopta para esgrimir la dualidad y ruptura entre las dos versiones de mujer propuestas. Por un lado, Janés coloca los verbos en pretérito en asociación con el pasado autoritario donde el sujeto se desenvolvía en un aceptado ambiente patriarcal. Por otro lado, el presente y el futuro se relacionan con la nueva biografía que el sujeto lírico está construyendo en el peregrinar que nos muestra la composición. Como también bien advierte Keefe Ugalde, aparecen "algunos aspectos de una subjetividad femenina autóctona" (1994, p. 177). En primer lugar, el sujeto lírico empieza a reconocer su cuerpo de mujer en correlación con su nueva identidad: "Por fin, no sé cómo, me vi disparada por / los aires / y empecé a palparme el cuerpo. / Por primera vez desde que nos separamos sentía el cuerpo.” (1975, p. 15). Y, en segundo lugar, una escena en la última fase de la composición en la que aparecen mujeres tejiendo juntas alude a la sororidad.

Sin embargo, aunque la conquista de la mujer emancipada como nueva identidad del sujeto lírico funciona como epicentro de la composición, debemos al mismo tiempo advertir que este proceso no se produce sin ambivalencias. Desde el título, la figura de Cordelia, la hija desheredada del rey Lear, nos sitúa ante conceptos como la obediencia -que finalmente acaba en tragedia-, y también apunta a otros, como advierten diferentes lecturas feministas del Rey Lear, tales como la aceptación de la represión y la sumisión. A mi juicio, en este caso, Cordelia simboliza la mujer desheredada que debe asumir, a la fuerza, su propia autonomía. Y, en este nuevo camino, se siente amenazada y se percibe cerca de la tragedia: "Porque cada vez hace un frío más intenso" (1975, p. 15). Según esta imagen de Cordelia, la identidad de la mujer está todavía por construirse, pero este proceso implica la ruptura con la mismidad pasada. En este sentido, en el poema es posible leer: "Pensé: este es el fin, / este es el comienzo." (1975, p. 12). Y, en ese comienzo, Cordelia se percibe como referente, pero al mismo tiempo también es desdeñada a lo largo de los versos. "Por suerte, Cordelia aún no sabe nada”, declara el yo lírico después de confesarse libre (1975, p. 14), para versos más adelante reafirmarse: "soy libre / ya no hay nada que esperar. / Cogeré a Cordelia / y me la llevaré lejos." (1975, p. 16). Hay más versos de este tipo, por ejemplo, al final de la composición donde se puede leer: "Y Cordelia miraba a las mujeres, me palpaba los brazos / y decía en voz baja: / 'yo quisiera ser cosa”" (1975, p. 31).

Además de la autónoma, pero cobarde Cordelia, aparecen otros personajes y símbolos a lo largo de la composición que merecen comentario. Uno de los personajes que se cita de manera recurrente es la vieja que claramente representa la definición de la mujer según el patriarcado. Sus obligaciones y mandatos convierten a la vieja en una perpetua amenaza, en un enemigo del que huir. Así la define: "escruta en mis ojos, escupe, / y me suelta que viene tu padre a comer, / y debo quedarme."; o más adelante: "Yo me empeñaba en explicar / que había que ser más generoso, / y ella insistía, / dale que te pego, / en que las cosas deben de estar cada una en su sitio / y al final quedar bien terminadas" (1975: 17). En la misma línea también se presenta el símbolo de la manta, muy activo a lo largo del poema, que, de acuerdo con la explicación de Janés, representa "el machismo que la mujer tiene que sufrir" (Keefe Ugalde, 1991, p. 42). En uno de los pocos momentos en los que el yo lírico se dirige directamente al tú-amado, aparece el símbolo de la manta: “De todos modos tú me debes todavía una manta / yo siempre, siempre / he querido perdonártelo. / Hace más de diez años que lucho por ello" (1975, p. 12).

Como se observa, en este proceso de conquista de la mismidad/mujer lo que parece claro es que el yo lírico se revuelve ante la identidad impuesta a las mujeres e incide sobre la falta de emancipación de estas. El poemario Libro de alienaciones incluye una imagen poderosa sobre el ridículo lugar en el que la sociedad coloca 
a las mujeres : "Érase una mujer / que bajo una implacable, incesante lluvia, / se esforzaba / todavía sin limpiar/ la barandilla del balcón de su casa / con una bayeta mojada” (1980, p. 80). También en este mismo libro, se define la subordinación a la que la sociedad empuja a la mujer cuando establece una relación sentimental con un hombre: "Aceptar el no ser ya con otro / Para que el otro sea. / [...] Reducirse voluntariamente a silencio perpetuo" (1980, p. 84). Tal y como termina En busca de Cordelia, la voz lírica a partir de estos poemarios ya es otra y la identidad de mujer se impondrá como un factor definitorio en las composiciones futuras:

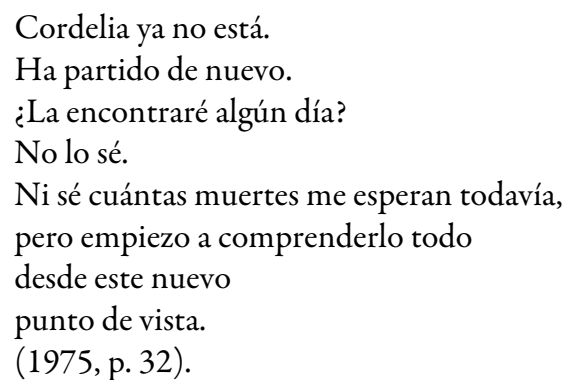

Una vez que se publica En busca de Cordelia, Janés decide enviárselo a Vladimír Holan a modo de agradecimiento por haber influido en este cambio de mirada lírica. Carlos Barral, editor de Holan en aquel momento en España, la pone en contacto con el traductor de su obra al español, Josef Forbelský, y este le hace llegar el poemario a Holan. Después de recibir respuesta de Holan, Janés decide en 1975 visitar Praga y organizar un encuentro con el poeta checo. En esta primera visita, Janés conoce a Holan junto a su esposa, Vèra Pilařová, su editor, Vladimír Justl, y Josef Forbelský. En aquella reunión, Janés, que todavía no hablaba checo, estuvo en un segundo plano y seguía la conversación gracias a las indicaciones de Forbelský. A pesar de que Holan no entabló de manera directa ninguna conversación con Janés, le pidió que volviera, petición que Janés no cumpliría hasta no aprender checo, dos años más tarde.

Janés no comprende la dimensión de este encuentro hasta la cuarta visita que le hace a Holan en el año 1979. El poeta checo estaba ya enfermo y no quería recibirla, pero Janés decidió que era buena idea llevarle de algún modo el mar de Barcelona y recogió algunas conchas y caracolas que acomodó en una caja con dos poemas que había escrito. En aquel momento, Janés trabajaba en la tercera parte de Kampa, que decidió ocultarle a Holan, porque "era el presentimiento de su muerte" (Janés, 2006, p. 53). En esta visita, Pilařová y Justl recibieron a Janés y Pilařová le entregó a Holan la caja con las conchas y los poemas. Janés escuchó a Holan llorar desde la habitación contigua y entonces Pilařová decidió revelar a Janés el enigma que había rodeado sus visitas.

En el año 1972, Holan había escrito Una noche con Ofelia, un largo poema que, en principio, había sido concebido a modo de continuación de Una noche con Hamlet. En esta composición se presenta a una Ofelia que era de Barcelona y que sale de un concierto del Orfeó Català para viajar por Europa hasta terminar en la República Checa, donde vista en Bohemia a Karel Hýnek Mácha, poeta checo del que Holan se sentía sucesor. Cuando Ofelia y Hýnek se encuentran, Ofelia le pregunta a Hýnek si tiene dinero. El poeta le dice que no y entonces Ofelia le ofrece conchas a modo de monedas.

Esta serie de coincidencias entre la Ofelia catalana de Holan y la biografía de Janés, también nacida en Barcelona, visitante frecuente durante su infancia del Palau de la Música de Barcelona al tocar Esther Nadal el clavicémbalo, y viajera por Europa hasta llegar a la República Checa, habían conducido a pensar a Vladimír Holan que estaba ante la materialización de uno de sus poemas: "Era una aparición, era un personaje que él había adivinado mucho antes de que yo hubiera tenido la intención de entrar en contacto con él. Supongo que mi mera concentración en su poesía había creado una extraña transmisión que él convirtió en poema" (Janés, 2006, p. 57). Esta trasmisión entre Holan y Janés también se percibe en la poesía que la autora catalana emprende, como veremos más adelante, después de En busca de Cordelia. El nexo entre Holan y Janés se convertirá, por tanto, en un signo definitorio de la poesía de ambos autores. 


\section{IDEOLOGÍA: HACIA LA CONQUISTA DE LO EXTERNO}

Aunque este proceso de re-iniciarse en una nueva identidad representa un cambio poderoso, no podemos perder de vista que es interno, individual, propio. Para que el cambio sea trascendente debe también implicar el exterior. En este paso hacia el exterior convergen las dificultades. Celia Amorós explica la oposición interior y exterior desde el punto de vista del género y advierte que históricamente estas categorías han sido asignadas, donde el dominio de la universalidad se asigna al hombre, mientras que la mujer, "no se orienta hacia lo universal, porque no es una conciencia o un sujeto lo suficientemente evolucionado en tanto que autoconciencia como para ser ciudadana de lo universal” (1990, p. 33). Amorós considera que en la superación de esta separación radica la lucha feminista: eserá posible que lo personal pueda salir de la plaza pública, que lo personal pueda ir al ágora, que lo personal se defina como algo susceptible de reconocimiento? (1990, p. 34).

Amorós con estos interrogantes enlaza con la máxima de la segunda ola del feminismo, "the personal is political" (Hanish, 1970), pero también nos hace reflexionar sobre la esfera oculta y silenciada a la que se confinan los problemas que provienen de lo femenino. La ruptura de esta burbuja y la traslación de estas cuestiones al debate público poseen un sentido claramente reivindicativo y que, en el caso de que se produzca y se legitime, provoca un verdadero cambio social.

En el caso de la poesía de Clara Janés la exteriorización marca los siguientes poemarios, Eros, Vivir y Kampa. En particular, el planteamiento del poemario Kampa, marcado por la relación y el encuentro con Holan, nos ofrece un yo lírico ampliado que desgaja los límites de su mismidad y los trasciende para desarrollarse a partir de la unión y de la fusión con otras identidades. En uno de los poemas de Kampa esta fusión con la identidad de Vladimir Holan se describe del siguiente modo:

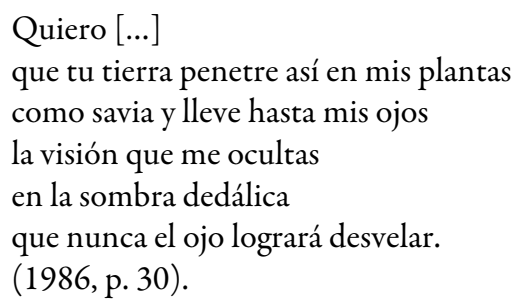

Esta fusión ha sido comentada por varias lecturas sobre esta obra. Rosa Chacel y María Zambrano destacaron el papel que la hablante lírica adquiere en esta obra cuando adquiere el rol tradicional del amante masculino que persigue a un "otro" que se adopta el papel de amado. De acuerdo con Anne M. Passero, en la segunda sección del poemario se percibe nítidamente esta inversión "donde una Eva revisada llega a ser intercambiable con Adán en una relación siempre en movimiento” (2015, p. 47). Sin embargo, no estamos únicamente ante un relato de conquista de ese "otro", sino más bien de aproximación y búsqueda de conocimiento y vida, en el que la construcción de la voz lírica se basa en la mística y en la música. Zambrano la caracterizaba del siguiente modo: "la voz no es hacia, ni sobre, ni porqué, en donde todo rastro se ha borrado; voz abismática, voz que sale sin romperlo del silencio, voz que está sobre el abismo, sostenida por la música" (1986, p. 3).

En efecto, la música impulsa el origen de este poemario, ya que esta se convierte en el primer elemento con el que Janés consigue penetrar en sus vivencias:

Inicio un susurro. Primero son sonidos, luego sílabas murmuradas que atraen a otras, forman palabras, se modifican, se rompen de nuevo. Y estos fragmentos atraen a otros sonidos, otras sílabas... Pero este hacerse y deshacerse del lenguaje sigue un hilo conductor, un hilo melódico que descubre el verdadero cuerpo del poema. Canto durante más de una hora, y esa melopea se adueña de la penumbra y de mí. (Janés, 2005b, p. 63) 
Este principio de elaboración lírica permite a Janés componer este poemario de un modo holístico en el que música y poesía permiten a la voz poética entrecruzar sus composiciones con las de Holan, indagar en sus referencias literarias y aglutinar en una misma entidad, como ya he anunciado, a la hablante lírica con el amado. A esta búsqueda de trascender en el otro, Rosa Chacel lo denominó "unión-comunión... o más bien fusión” (1986, p. 101), John C. Wilcok caracterizó a esta voz lírica como un ser reengendrado (1989, p. 360), y Keefe Ugalde determinó a este proceso “osmosis” (1993, p. 199).

A esta idea de fusión y ambivalencia entre sujeto y objeto lírico, se ha superpuesto la cuestión del erotismo en Kampa presente en algunos pasajes de este libro, por ejemplo, cuando la hablante lírica ofrece su cuerpo al amado para robar a la muerte algunos días (1986, p. 38). Esta vertiente erótica no es exclusiva de Kampa y se percibe en otros libros anteriores como Vivir y Eros. En esta línea, habría que situar uno de los poemas más famosos de la poesía janesiana y que da cuenta de este impulso hacia la trascendencia. Me estoy refiriendo a la composición "Convite" del libro Vivir:

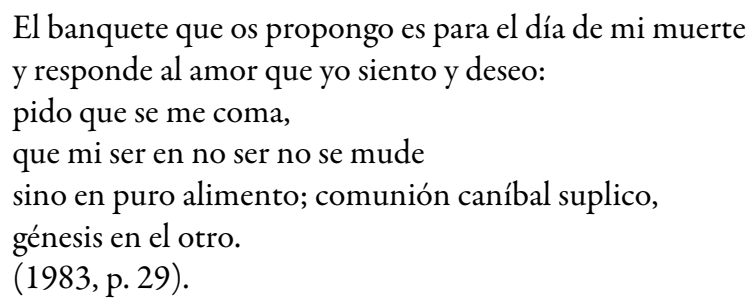

Ese afán de fundirse con el cosmos nos ofrece, de acuerdo con Ana Garriga (2014, p. 59), un particular misticismo en cuyo extremo, tal y como nos presenta este poema, se encuentra la antropofagia. Sin embargo, pienso que no hay que perder de vista que el erotismo es una vertiente más de este afán de exteriorización, de este superar el límite del interior, pero no creo que se deba confundir con el principio que origina la transcendencia. De hecho, en otras composiciones de Vivir, la poetización se orienta hacia el universo de lo cotidiano manteniéndose, por tanto, el foco lírico hacia lo externo. Aquí se sitúa la sección "Presencia" dedicada a poetizar animales como la mariposa (1983, pp. 35-37), el búho o la paloma, y "Lindareja" donde el yo lírico se dirige hacia el paisaje (1983, pp. 41-48). Como ejemplo, cito los versos del poema Castilla: "Castilla parcheada de abrojos, / ¡cuánta sed te atormenta! / En mis ojos se forman dos largos incesantes / para calmar tus resecas heridas, / mi amante mano te siembra de esmeraldas." (1983, p. 45). Del mismo modo, el poemario Eros se presenta como un buen ejemplo de la subordinación del erotismo con respecto a este afán de lograr conquistar lo exterior.

Antes de transitar los poemas de Eros, pienso que es útil recuperar la idea de Celia Amorós sobre la necesidad de hacer pasar la reivindicación de la mujer por la externalización del universo ocultado por la tradición patriarcal. Algunas de las víctimas de este afán de silenciar el universo propio de la mujer han sido el erotismo y el sexo femeninos. Dedicar un poemario al erotismo de la mujer supone traspasar esta frontera de ocultación y, al mismo tiempo, supone asumir un nuevo discurso sobre la mujer en la sociedad. De este modo, pienso que para explicar el poemario Eros, publicado en 1981, hay que atender a las reivindicaciones del feminismo español de la Transición que no solo lucharon por legitimar a la mujer en el contexto de la democracia, sino también por exteriorizar debates como el aborto, el lesbianismo o la sexualidad de la mujer. Figuras como la citada Celia Amorós, otras muy conocidas como Lidia Falcón, o los trabajos de Concepción Cifrián, Isabel Serrano y Carmen Martínez Ten (1986) sobre el aborto, los de Raquel Osborne (1986) sobre la prostitución o los de Victoria Sau $(1980,1976)$ acerca del lesbianismo y del matrimonio publicados en estos años pueden servir como ejemplo de esta corriente. En este contexto, versos del poemario Eros como "Sus yemas insaciables se centran en la vulva, inician nueva forma de oración" (1981, p. 50) o "Estuve con un joven / Y supe al fin lo que era / El violento arrebato, la agilidad vibrátil” (1981, p. 45) en los que se nombra la genitalidad femenina y en los que se expresa el disfrute de la sexualidad de la mujer se sitúan más allá de una simple expresión lírica del erotismo y deben entenderse como un posicionamiento del erotismo 
de la mujer fuera de la esfera de lo oculto y, por ende, como una reivindicación a favor de una nueva mujer emancipada y libre.

\section{Conclusión}

Pienso que el grupo de poemarios estudiados, Las estrellas vencidas (1964), Limite humano (1973), En busca de Cordelia (1975), Libro de alienaciones (1980), Eros (1981), Vivir (1983) y Kampa (1986), deben ser acogidos como formantes de una misma cadena que podríamos definir como la conquista de la mismidad de la mujer. En este proceso, como hemos visto, es posible distinguir tres etapas, la de la ruptura, la de la experiencia personal y la de la externalización reivindicativa. En este proceso se advierten, de igual modo, dos hitos fundamentales. El primero de ellos es el descubrimiento que realiza Clara Janés de la poesía de Vladimír Holan. Este hallazgo provoca que Janés se libere de las fórmulas compositivas de su primera etapa y abogue por una nueva fórmula de poetización que se iniciará a partir de En busca de Cordelia. Esta nueva perspectiva creativa aunada a una crisis sentimental orienta la poesía jarnesiana a interrogarse por la identidad en clave femenina. En la búsqueda de esta nueva mismidad, se aprecia cómo la voz lírica evoluciona y ocupa posiciones cada vez más emancipadas e independientes de los roles asignados para la mujer por el patriarcado. Sin embargo, cuando esta nueva identidad se enfrenta con el alrededor, se percibe todavía en esta segunda etapa un yo lírico titubeante que no se consolidará hacia la tercera fase de este proceso. En este último eslabón interviene el segundo de los hitos señalados. Me refiero a la eclosión de los años ochenta del feminismo español que consigue situar en el centro del debate público la liberación de la mujer. Cuestiones como el aborto, el lesbianismo o la sexualidad se abordan por primera vez en la sociedad democrática y consiguen fraguar un contexto social en el que la mujer se confronta sin tantas restricciones con el exterior. En esta tercera etapa, Janés publica poemarios como Vivir, Eros y Kampa en los que el sujeto lírico supera los límites de la intimidad y, desde la nueva mismidad sustentada en su identidad como mujer, indaga el paisaje cotidiano, se fusiona con otras identidades y experimenta una sexualidad más libre. De este modo, el erotismo presente a lo largo de los versos de esta última etapa se concibe como un signo más de esta conquista del exterior. En definitiva, estos poemarios ofrecen a una hablante poética capaz de convertir el tránsito identitario desde el interior al exterior en una lírica que nos muestra cómo enfrentar, desde la perspectiva la mujer, la vida en sociedad y en libertad.

\section{ReFERENCIAS}

Amorós, C. (1990). Mujer. Participación, cultura politica y estado. Buenos Aires: Ediciones de La Flor.

Chacel, R. (1986). Epílogo. En: C. Janés, Kampa (pp. 98-101). Madrid: Hiperión.

Engelson Marson, E. (1995). Clara Janés: Mysticism and the Search for the Female Poetic Voice. Revista de Estudios Hispánicos, 29(2), 245-257.

Cifrián, C., Serrano Pintado y Martínez Ten (1986). La cuestión del aborto. Madrid: Icaria.

Garriga Espino, A. (2014). 'Pido que se me coma, / que mi ser en no ser se mude’: misticismo y poesía en Clara Janés. Confluencia, 30(1), 57-71.

Hanish, C. (1970). The personal is political. Notes from the Second Year: Radical Feminism, 2, 76-77.

Holan, V. (1970). Una noche con Hamlet y otros poemas. Barcelona: Seix Barral.

Janés, C. (julio-agosto, 1961). Poema. Cuadernos de Ágora, 57-58, s.p.

Janes, C. (enero-abril, 1963). En cada esquina. Cuadernos de Ágora, 63-66, s.p.

Janés, C. (1964). Las estrellas vencidas. Madrid: Ágora.

Janés, C. (1973). Limite humano. Madrid: Oriens.

Janés, C. (1980). Libro de alienaciones. Madrid: Ayuso. 
Janés, C. (1981). Eros. Madrid: Hiperión.

Janés, C. (1983). Vivir. Madrid: Hiperión.

Janés, C. (1986). Kampa. Madrid: Hiperión.

Janés, C. (2005a). La voz de Ofelia. Madrid: Siruela.

Janés, C. (2005b). El espejo de la noche. A Vladimir Holan en su centenario. Estudios y conversaciones. Madrid: Adamaramada Ediciones.

Janés, C. (2006). La gruta de las palabras. Oviedo: Universidad de Oviedo.

Janés, C. (2014). Introducción. En: V. Holan, La gruta de las palabras (pp. 7-25). Barcelona: Galaxia Gutenberg.

Keefe Ugalde, S. (1990). La subjetividad desde 'lo otro’ en la poesía de María Sanz, María Victoria Atencia y Clara Janés. Revista Canadiense de Estudios Hispánicos, 14(3), 511-523.

Keefe Ugalde, S. (1991). Conversaciones y poemas. La nueva poesia femenina española en castellano. Madrid: Siglo XXI.

Keefe Ugalde, S. (1993). Huellas de mujer en la poesía de Clara Janés. Anales de Literatura Española Contemporánea, 18(1/2), 193-209.

Keefe Ugalde, S. (1994). El 'poema largo' femenino en la España actual. En: J. Villegas Morales (coord.), La mujer y su representación en las literaturas hispánicas (pp. 173-180). California: University of California Press.

Lamas, M. (1994). Cuerpo: diferencia sexual y género. Debate feminista, 10, 3-31.

Martin Hernandez, É. (2014). La voz de Ofelia. Une voix déployée. Bulletin Hispanique, 116(2), 563-570.

Nadal, E. (1962). Carta a Concha Lagos. Ms. 22654/110. Madrid: Biblioteca Nacional de España.

Pasero, A. M. (2015). Intertextualidad de arte y vida en obras recientes de Clara Janés: Una perspectiva femenina. Ámbitos. Revista de estudios de ciencias sociales y humanidades, 33, 45-52.

Payeras Grau, M. (2009). Espejos de palabra. La voz secreta de la mujer en la poesía española de posguerra (1939-1959). Madrid: UNED.

Payne, S. (1982). El fascismo. Madrid: Alianza Editorial.

Rodríguez Puértolas, J. (1986). Literatura fascista española I. Historia. Madrid: Akal.

Osborne, R. (1986). Feminismo y prostitución: buenas intenciones y malas comprensiones. Sistema. Revista de ciencias sociales, $74,73-88$.

Ostriker, A. (1986). Stealing the language. The emergence of women's poetry in America. Boston: Beacon Press.

Porro, M. J., Sánchez Dueñas, B. (2015). Concha Lagos, agente cultural: los Cuadernos de Agora. Madrid: UNED.

Sau Sánchez, V. (1976). Mujer: matrimonio y esclavitud. Gijón: Júcar.

Sau Sánchez, V. (1980). Mujeres lesbianas. Madrid: Zero.

Wilcok, J. C. (1989): Clara Janés: hacia su poemario de los años ochenta. En: A. Vilanova (ed.), Actas del X Congreso de la Asociación de Hispanistas III (pp. 333-361). Barcelona: Promociones y Publicaciones Universitarias.

Zambrano, M. (7/12/1986). La voz abismática. Culturas. Diario 16, 3.

\section{Notas}

1 Con anterioridad, Holan había transitado una primera etapa simbolista cercana a la vanguardia donde sus poetas de referencia son Rainer Maria Rilke, Stéphane Mallarmé y Paul Valery - Abanico en delirio (1926), Triunfo de la muerte (1930), Soplo (1930), Arco (1934), Piedra, vienes (1937)-. Su fascinación por la metáfora lo lleva a colaborar con el romanista Václav Černý en la traducción al checo de la Fábula de Polifemo y Galatea en 1939, Báje o Ákidu i Galatii. Sin embargo, cuando Checoslovaquia es ocupada por las tropas nazis, Holan abandona este estilo, se afilia al Partido Comunista -aunque no tarda en abandonarlo al igual que otros poetas checos de su misma generación- y el mensaje de sus obras se entrega a favor de la liberación -Respuesta a Francia (1938), Septiembre (1938), Sueño (1939), Canto de los tres reyes (1939), Primer testamento (1939-1940), Terezka Planetová (1943), Soldados del ejército rojo (1947)-. Una vez que acaba la II Guerra Mundial y, a pesar del compromiso político asumido, los comunistas lo tildan de formalista trasnochado lo que provoca que sus obras dejen de publicarse. Es entonces cuando Holan decide retirarse a la isla de Kampa en 1948 y encerrase en casa - "muro por muro" dijo (Justl, 1964, p. 6)-, además comienza a vivir y escribir de 
noche, práctica por la que el poeta Seifert Jaroslav lo empezó a denominar el “ángel negro” y que lo convirtió en un mito viviente. Durante este encierro escribe su poesía más existencial y ontológica y aunque su reclusión ya no se quebrará, su obra comienza a salir del ostracismo al que la habían confinado en 1963 y empieza a reconocerse a nivel europeo -por orden de publicación, las obras de esta etapa son Sin titulo (1963), Toscana (1963), Avanzando (1964), Dolor (1964), Una noche con Hamlet (1964), En el último trance (1967), Un gallo para Esculapio (1970) o Una noche con Ofelia (1973), entre otras- (Janés, 2005a, p. 2014). 